\title{
No Plunging and Cold Maceration followed by No Plunging as Alternative Winemaking Techniques: Tannin Extraction and Pigment Composition of Syrah and Pinot Noir Wines
}

R. Chittenden*, P. King

School of Viticulture and Wine Science, Eastern Institute of technology, Private Bag 1201, Hawkes Bay Mail Centre, Napier, New Zealand.

Submitted for publication: May 2019

Accepted for publication: March 2020

Key words: Anthocyanin, pigmented tannin, tannin, phenolics, maceration, Syrah, Pinot Noir

\begin{abstract}
Three different cap management maceration techniques were compared using Syrah (2015) and Pinot Noir (2016). The control, Traditional maceration (TM), of two plunges per day for 15 days total maceration was compared with a No Plunge (NP) trial and a Cold Maceration followed by No Plunge (CM) trial. Total phenolic, tannin and colour extractions were compared during and post maceration using the AWRI WineCloud $^{\mathrm{TM}}$. Differences were noted for both varieties. The Pinot Noir wine CM trial developed higher extractions and more stable colour over time compared with the NP and TM trials. Whereas with the Syrah wine, both the CM and NP trials displayed higher total phenolic, tannin and colour extractions with more stable colour over time compared with the TM trial.
\end{abstract}

\section{INTRODUCTION}

Red wine components considered to be essential contributors to colour and astringency and bitterness include proanthocyanidins, also known as condensed tannins. They are examples of polymer flavonoid compounds (Gawel, 1998). Winemaking teams employ processes involving significant time and effort to ensure these compounds are extracted from grape solids and into the resulting wine (Ribereau-Gayon et al., 2006; Sacchi et al., 2005).

As tannins are important to overall red wine quality it is of interest to investigate the effectiveness of physical cap management processes in the extraction of skin and seed tannins. Tannins found in these structures are flavonoid based proanthocyanidins (Kennedy \& Jones, 2001; Kennedy \& Hayasaka, 2004). It is believed skin tannins are generally higher in molecular mass than seed tannins and that this may cause differences in relative rates of extraction (Kennedy $\&$ Taylor, 2003). Extractions can vary due to fruit maturity, maceration time, enzyme use and cap management.

It is generally assumed that, to a point, extraction of tannins and anthocyanins leads to increases in wine quality in the resulting wines (Kassara \& Kennedy, 2011; Mercurio et al., 2010). Established cap management techniques are believed to encourage this, such that increased cap management leads to increased ease of extraction (de Beer et al., 2006; Gao et al., 1997; Gil et al., 2012; Kovac et al., 1992; Sacchi et al., 2005). On the other hand, research into minimal (no) cap management in relation to tannin and anthocyanin extraction is scarcer. Chittenden et al. (2015) explored a no plunging regime effect on proanthocyanidin extraction with red wines made using Merlot, finding that phenolic and anthocyanin extractions were lower in the traditional maceration treatment compared with the no plunge treatment. Lerno et al. (2018) used research scale Cabernet Sauvignon fermentations to show that pump over volume and frequency were found to have no significant effect on phenolic extraction. Bosso et al. (2011) suggest that a higher tannin concentration in submerged cap, no pump over, wine may be due to higher retention of tannins and maybe not higher extraction.

Studies into the effects of cold maceration (CM) on extraction of anthocyanins and proanthocyanidins have produced varied and conflicting results. These have been summarized in a review by Aleixandre-Tudo \& du Toit (2018). They report on studies which show no effect and studies which show increased phenolic and anthocyanin extraction as a result of CM (Busse-Valverde, 2011; GilMunoz et al., 2009; Gomez- Miguez et al., 2007) also studies showing little change or decreases in phenolic extraction (Gonzales- Neves et al., 2010; Puertas et al., 2008; Sacchi et al., 2005).

Other CM studies suggest phenolic extraction variations with regard to $\mathrm{CM}$ may be varietal and temperature dependent (Busse-Valverde et al., 2010). Finding that anthocyanin levels in finished wines were similar to wines produced 
without CM. Cassassa et al. (2015) found that a CM at $4{ }^{\circ} \mathrm{C}$ had no significant effect on basic chemical composition of finished Pinot Noir and Syrah wines although the wines were saturated with higher red components than the TM wine. The Pinot Noir wine had lower anthocyanin levels than the Syrah. They attributed the no effect of CM to low CM temperatures and to the difference between Pinot Noir and Syrah skin cell wall. Marais et al. (2003) found no significant increase in phenolic levels in wines produced using Pinotage grapes when a $10^{\circ} \mathrm{C} \mathrm{CM}$ was applied compared with a TM treatment.

The work presented in this study continues to explore minimal (no) cap management (NP) and its effect on proanthocyanidin extraction. Syrah (2015) and Pinot Noir (2016) were chosen as single varietal red wine styles with particularly the Pinot Noir being a cultivar exhibiting lower proanthocyanidin extractions compared with other red varietals (Lee, 2010; Parley et al., 2001; Sparrow et al., 2015). Further information regarding minimal (no) management and the effects on extraction of proanthocyanidins into red wine will enhance the understanding of cap management techniques, giving winemakers greater ability to identify the required processes needed to reach desired extraction concentrations. In addition in this study a further no cap management trial together with a pre fermentation cold maceration (CM) was also carried out. Cold soak or cold preferment maceration $(\mathrm{CM})$ has been used in red wine making as a means of producing wines with increased colour, colour stability and overall proanthocyanidin levels. An aim of this study was to evaluate any differences in anthocyanin and proanthocyanidin extractions using CM for wines made from Syrah and Pinot Noir grapes.

\section{MATERIALS AND METHODS}

Three replicate trials were undertaken in 2015 using Syrah and in 2016 using Pinot Noir with grapes sourced from commercial wineries in Hawke's Bay. Materials and method for the grape processing were as reported by Chittenden et al (2015).

Must analysis using methods of Iland et al. (1993) determined Syrah composition as $22.0^{\circ}$ Brix, $6.8 \mathrm{~g} / \mathrm{L}$ tartaric acid equivalent titratable acidity and $\mathrm{pH}$ of 3.36 and Pinot Noir composition as $22.5^{\circ} \mathrm{Brix}, 7.0 \mathrm{~g} / \mathrm{L}$ tartaric acid equivalent titratable acidity and $\mathrm{pH} 3.26$. The ferments and wines were analysed using the Australian Wine Research Institute WineCloud $^{\mathrm{TM}}$ (AWRI, 2012), as previously described and reported Chittenden et al (2015). Table 1 describes details of the three trial methods.

Relative colour, pigment, phenolics and tannin data were generated via the WineCloud ${ }^{\mathrm{TM}}$ based on algorithms for this purpose using the described absorbance's to generate the relative data presented (Chittenden et al., 2015). These absorbance's are based on results from analyses according to the modified Somers and Evans assay (1977), as reported by Mercurio, D et al (2007) and Dambergs et al (2012).

The statistical analysis of all the data was expressed as the arithmetic average of three replicates. ANOVA was conducted using Minitab 17.1.0.0. Tukey's procedure was used to indicate significance at the $p<0.05$ level.

\section{RESULTS AND DISCUSSION}

Wine composition parameters are shown for Syrah (Table 2) and Pinot Noir (Table 3). The TM Syrah had a lower alcohol concentration compared with other Syrah treatments, the TM Pinot Noir had higher titratable acidity and lower $\mathrm{pH}$ compared with other Pinot Noir treatments. These differences were small and not consistent from year to year or variety to variety. However, all parameter concentrations for the wines produced were within ranges reported in the literature for Syrah and Pinot Noir wines (Gao et al., 1997; Kemp et al., 2011; Lattey et al., 2010)

The 2015 Syrah trial, shown in Fig. 1, both the NP and $\mathrm{CM}$ wines showed higher tannin concentrations during maceration from day 6 compared with the TM treatment. This is in agreement with the 2013 Merlot trials reported by Chittenden et al. (2015). Tannin concentrations increased post pressing in both years. The Pinot Noir trials of 2016, shown in Fig. 2, however showed higher tannin extraction only in the CM treatment during maceration with the NP treatment being no different to the TM. Further all Pinot Noir treatments plateaued post pressing unlike the Syrah post pressing trends which showed increases in all three treatments. Total phenolic concentration trends were similar to the tannin trends in each of the respective two years. (Results not reported)

The results of the 2015 Syrah trial (Fig. 3) again showed similar total pigment concentration trends to the 2013 Merlot study (Chittenden et al., 2015). Being higher in the NP treatment compared with the CM and TM treatments over the maceration 6-15 day period, with $\mathrm{CM}$ and NP being no different post pressing and greater than TM over the next

TABLE 1

2015 Syrah and 2016 Pinot Noir trials

\begin{tabular}{llll}
\hline & Traditional Maceration (TM) & No Plunge (NP) & Cold Maceration (CM) \\
\hline Maceration & $\begin{array}{l}\text { Classical 15 day fermentation } \\
\text { and skin contact. 12 plunges per } \\
\text { replicate 2 times per day }\end{array}$ & $\begin{array}{l}\text { No plunging of cap during 15 day } \\
\text { fermentation and skin contact }\end{array}$ & $\begin{array}{l}5 \text { day pre fermentation aqueous } \\
\text { skin contact. Followed by rapid } \\
\text { warming inoculation and the NP } \\
\text { regime for } 15 \text { days }\end{array}$ \\
$\begin{array}{llll}26-33^{\circ} \mathrm{C} \text { in a } 26^{\circ} \mathrm{C} \text { temperature } \\
\text { controlled room, } 15 \text { days }\end{array}$ & $\begin{array}{l}26-33^{\circ} \mathrm{C} \text { in a } 26^{\circ} \mathrm{C} \text { temperature } \\
\text { controlled room, } 15 \text { days }\end{array}$ & $\begin{array}{l}-2^{\circ} \mathrm{C} \text { during Cold maceration } \\
\text { followed by } 26-33^{\circ} \mathrm{C} \text { for } \\
\text { fermentation and further skin } \\
\text { contact in } 26^{\circ} \mathrm{C} \text { temperature } \\
\text { controlled room }\end{array}$ \\
\hline
\end{tabular}


TABLE 2

General composition of 2015 Syrah wines. Mean values $(n=3) \pm$ standard deviations. Values with the same letter in the same columns mean that there are no statistically significant differences according to a Tukey test $(\mathrm{p}<0.05)$. Titratable Acidity expressed as g/L tartaric equivalent; Volatile Acidity as g/L acetic acid equivalent; Alcohol as \%( v/v); Residual Sugar in glucose g/L. TM.-Traditional maceration. CM Cold Maceration followed by No Plunge cap management. NP. No Plunge cap management.

\begin{tabular}{lllll}
\hline Variety & Winemaking & Titratable Acidity & $\mathrm{pH}$ & Volatile Acidity \\
\hline \multirow{3}{*}{ Syrah } & TM & $6.0 \mathrm{a} \pm 0.04$ & $3.65 \mathrm{~b} \pm 0.01$ & $0.507 \mathrm{a} \pm 0.033$ \\
& $\mathrm{CM}$ & $5.9 \mathrm{a} \pm 0.10$ & $3.67 \mathrm{a} \pm 0.00$ & $0.629 \mathrm{a} \pm 0.103$ \\
Variety & $\mathrm{NP}$ & $6.2 \mathrm{a} \pm 0.19$ & $3.67 \mathrm{a} \pm 0.00$ & $0.738 \mathrm{a} \pm 0.139$ \\
& Winemaking & Alcohol & Residual Sugars & \\
\multirow{2}{*}{ Syrah } & TM & $12.3 \mathrm{c} \pm 0.06$ & $1.7 \mathrm{a} \pm 0.17$ & \\
& $\mathrm{CM}$ & $12.6 \mathrm{~b} \pm 0.06$ & $2.1 \mathrm{a} \pm 0.12$ & \\
\hline
\end{tabular}

TABLE 3

General composition of 2016 Pinot Noir wines. Mean values $(n=3) \pm$ standard deviations. Values with the same letter in the same columns mean that there are no statistically significant differences according to a Tukey test $(\mathrm{p}<0.05)$. Titratable Acidity expressed as g/L tartaric equivalent; Volatile Acidity as g/L acetic acid equivalent; Alcohol as \%( v/v); Residual Sugar in glucose $\mathrm{g} / \mathrm{L}$.

\begin{tabular}{lllll}
\hline Variety & Winemaking & Titratable Acidity & $\mathrm{pH}$ & Volatile Acidity \\
\hline \multirow{2}{*}{ Pinot Noir } & $\mathrm{TM}$ & $5.9 \mathrm{a} \pm 0.06$ & $3.54 \mathrm{~b} \pm 0.03$ & $0.268 \mathrm{a} \pm 0.011$ \\
& $\mathrm{CM}$ & $5.6 \mathrm{~b} \pm 0.06$ & $3.72 \mathrm{a} \pm 0.04$ & $0.238 \mathrm{a} \pm 0.025$ \\
Variety & $\mathrm{NP}$ & $5.6 \mathrm{~b} \pm 0.06$ & $3.58 \mathrm{~b} \pm 0.05$ & $0.289 \mathrm{a} \pm 0.056$ \\
& Winemaking & Alcohol & Residual Sugars & \\
Pinot Noir & $\mathrm{TM}$ & $12.8 \mathrm{a} \pm 0.23$ & $1.8 \mathrm{a} \pm 0.25$ & \\
& $\mathrm{CM}$ & $13.2 \mathrm{a} \pm 0.12$ & $1.9 \mathrm{a} \pm 0.06$ & \\
\hline
\end{tabular}

year. Total pigments levels decreased in all treatments post pressing. However, Fig. 4 shows the Pinot Noir total pigment results in 2016 differed in that the CM treatment had greater total pigment levels than the NP treatment which in turn was greater than the TM treatment over the second half of the 15 day maceration time. Increased extraction of $\mathrm{K}^{+}$which can lead to higher potassium bitartrate precipitation rates have been reported and proposed as having an effect in removing colour (Bosso et al., 2011). Post pressing both Pinot Noir $\mathrm{CM}$ and NP continued to show greater total pigment than TM to day 307 and all were decreasing over this time.

Syrah free anthocyanins were found at higher concentrations in the NP treatment (Fig. 5) compared with the TM during the 15-day maceration, with maximums reached on about day 6. Similar results were found with Merlot previously (Chittenden et al., 2015). For the NP Syrah treatment free anthocyanin concentrations were also greater than for the $\mathrm{CM}$ treatment during this time period. After pressing both CM and NP free anthocyanin levels remained higher than the TM treatment with all values then decreasing. So that by day 324 in the Syrah trial there was no significant difference between treatments. This contrasts to a 2013 Merlot study (Chittenden et al., 2015) where an NP treatment had higher free anthocyanins at 11 months compared with the TM treatment. Pinot Noir, as shown in Fig. 6 displayed different trends in that by day 14 of the maceration period the $\mathrm{CM}$ free anthocyanin concentration was greater than the NP which was in turn greater than the TM treatment. And this difference continued until day 170 . Cap temperatures are greater for longer in the no plunge treatments (NP and CM) compared with TM treatments as they are not cooled periodically during pump overs or plunging. Increased cap temperatures during fermentation can lead to increased monomeric anthocyanin extraction (Gao et al., 1997). Post day 170 the Pinot Noir CM treatment levels of free anthocyanins decreased to below the NP treatment levels which was in turn greater than the TM treatment free anthocyanin levels. In all treatments for all year's free anthocyanin decreased post pressing.

Syrah pigmented tannin levels (Fig. 7) during the 15-day 


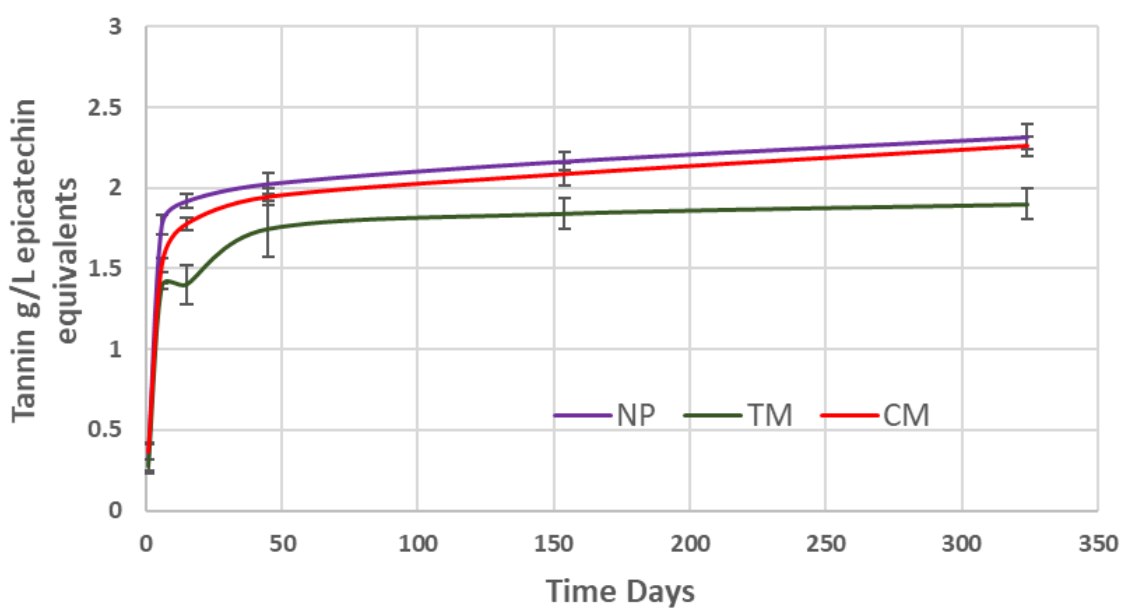

FIGURE 1

2015 Syrah tannin contents of the three winemaking procedures beginning at day 1 , expressed as $\mathrm{g} / \mathrm{L}$ epicatechin equivalents.

TM. Traditional maceration. NP. Not plunged. CM Cold maceration and not plunged. N $=3$ Error Bars \pm 1 Std Dev.

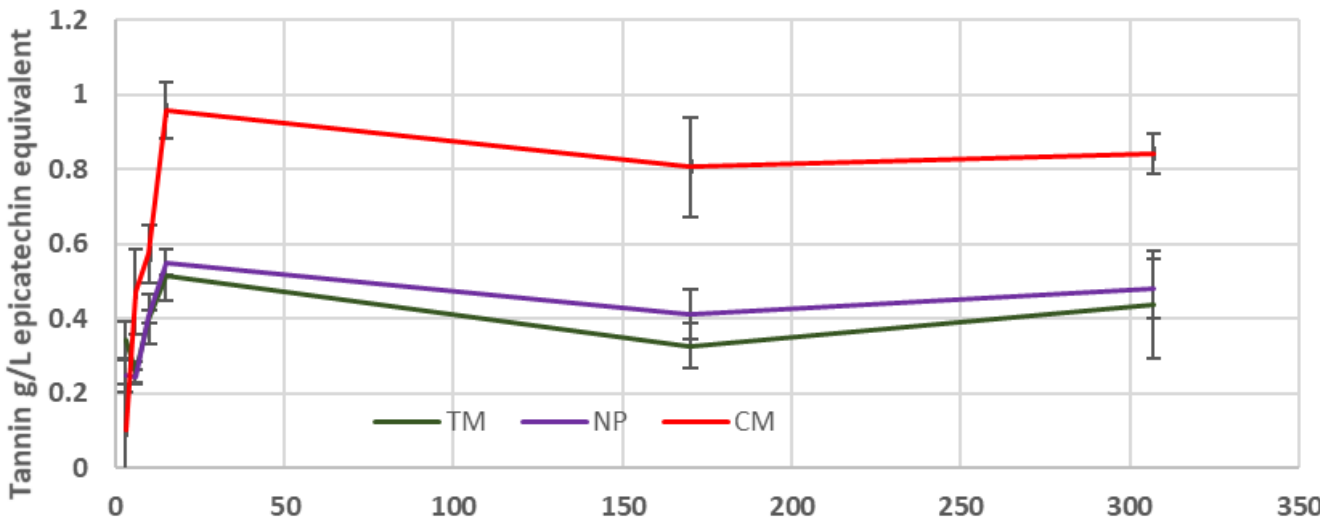

Time Days

FIGURE 2

2016 Pinot Noir tannin contents of the three winemaking procedures beginning at day 1, expressed as $\mathrm{g} / \mathrm{L}$ epicatechin equivalents.

TM. Traditional maceration. NP. Not plunged. CM Cold Maceration and not plunged. N $=3$ Error Bars \pm 1 Std Dev.

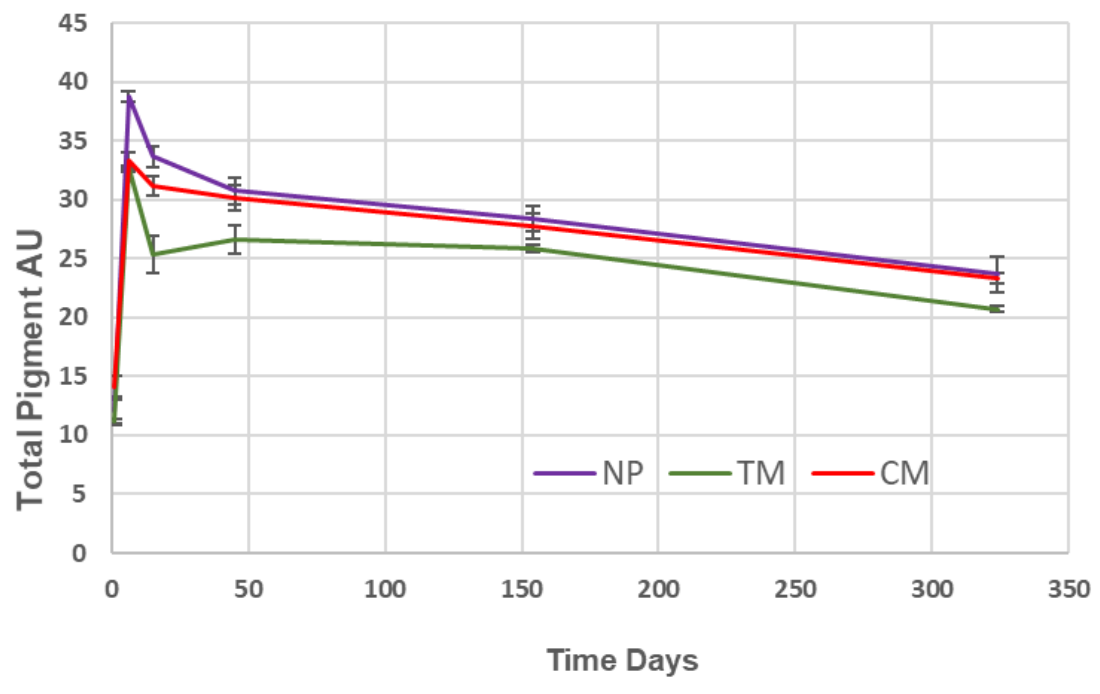

FIGURE 3

2015 Syrah total pigment content of the three winemaking procedures, beginning at day 1, expressed in Absorbance Units. TM.

Traditional maceration. NP. Not plunged. CM Cold Maceration and not plunged. $\mathrm{N}=3$ Error Bars \pm 1 Std Dev. 


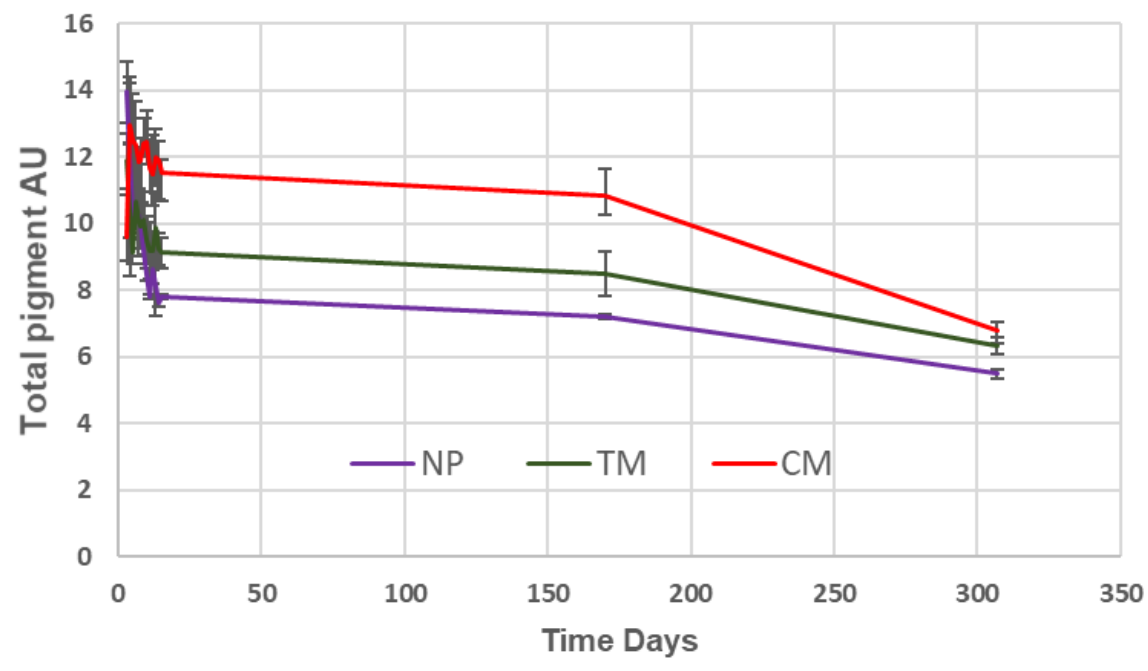

FIGURE 4

2016 Pinot Noir total pigment content of the three winemaking procedures, beginning at day 1, expressed in Absorbance Units. TM. Traditional maceration. NP. Not plunged. CM Cold Maceration and not plunged. N=3 Error Bars \pm 1 Std Dev.

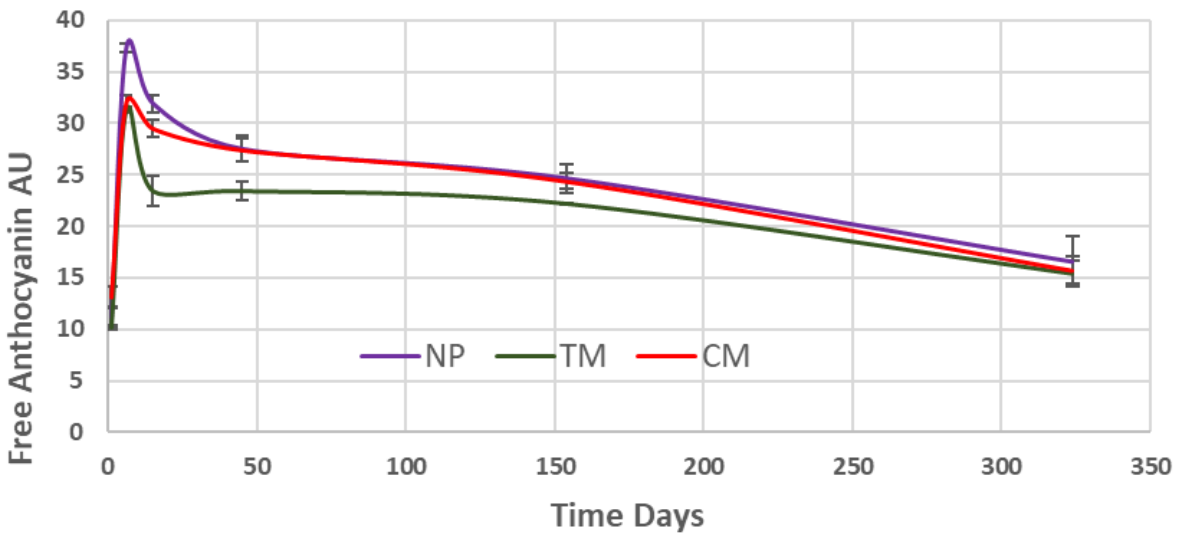

FIGURE 5

2015 Syrah free anthocyanin content of the three winemaking procedures, beginning at day 1, expressed as Absorbance Units. TM. Traditional maceration. NP. Not plunged. CM Cold Maceration and not plunged. N=3 Error Bars \pm 1 Std Dev.

maceration period for the NP and TM treatments showed little differences and only a marginally greater level was found in the CM trial. This agrees with pigmented tannin development found in the 2013 Merlot trials during 15 days maceration (Chittenden et al., 2015). However by days 45 through to 324 there were no significant differences between pigmented tannin levels in all three Syrah treatments, whereas the 2013 Merlot trial NP treatment displayed greater pigmented tannin levels compared with the Merlot NP treatment post pressing days 150 to 350 (Chittenden et al., 2015). The pigmented tannin concentrations in all treatments of the Syrah continued to increase post pressing. Fig. 8 shows that with Pinot Noir from 2015 pigmented tannins were higher in the CM treatment up to day 7 during maceration compared with the other two Pinot Noir treatments. By day fifteen all three pigmented tannin levels were similar for the three different Pinot Noir treatments. Pigmented tannin level increased after day 170 in the Pinot Noir CM treatment, whereas the TM and NP treatments maintained similar and somewhat lower levels at day 307.

In summary the Syrah 2015 varietal trials produced NP and CM wines after one year with higher levels of tannin, total phenolics, total pigment and pigmented tannin compared with wines derived from the TM treatment. Free anthocyanin levels were similar after 1 year. These results agree with a Merlot 2013 trial (Chittenden et al., 2015) with the exception of free anthocyanin extractions. Bosso et al. (2009) looked at using decreased frequency of pump overs early in maceration and separating musts as alternative anthocyanin extraction regimes. They found in both cases wines produced post pressing were higher in colour, total and monomeric pigment and total phenolics than wines produced using traditional pump over techniques as reported by Chittenden et al. (2015). In an exploration of temperature effects on phenolic extraction using Cabernet Sauvignon Lerno et al. (2015) found during extended maceration the higher temperature fermentations extracted higher levels of seed phenolics although skin derived phenolics showed 
decreased extraction, probably due to secondary reactions. In a further study Bosso et al. (2011) report that in a submerged cap compared to floating cap trial using pump overs the submerged cap wines had lower concentrations of pigmented tannins early in the maceration period but higher monomeric anthocyanin concentrations and inferred this may be due to increased oxygen contact as a result of mechanical cap management such as pump overs and plunging. This result is more consistent with the 2015 Syrah trials of this study.

In the Pinot Noir trials of 2016 however, only the CM trial showed higher tannin and total phenolic levels in wine after about 1 year with NP and TM being similar and lower. Total pigment levels were higher in the CM and NP Pinot Noir treatments, as was found with the Syrah trial. Free anthocyanin levels decreased markedly in the Pinot Noir CM treatment after 170 days but not in the NP and TM treatments. This decrease, however, corresponded to a sharp increase in pigmented tannin levels in the CM Pinot Noir trial after 170 days. A similar change during the second half of the wine aging also occurred albeit to a less extent in the Syrah CM treatment.

The two fundamental differences between the Syrah trials compared with the Pinot Noir trial are of interest. Namely for Syrah the CM and NP treatments produced similar extraction gradients and were in general higher in phenolics than the TM treatment throughout maceration and over the next 11 months. However for Pinot Noir the NP treatment followed similar extraction trends to the TM and both were consistently lower than the CM treatment. The CM treatment resulted in higher apparent extractions for Pinot Noir but not for Syrah, when taken in isolation. These results are discussed further and compared with other published material.

In a study Gonzales-Neves et al. (2013) found CM over five days increased colour intensity and total polyphenol (anthocyanin and Proanthocyanidins) in Tannat and Merlot wines compared with TM treatments. However this treatment had no effect on Syrah wine proanthocyanidin levels. This result agrees with results for CM Syrah wines presented in this study. The results of the current study and these previous studies tend to confirm the varietal and temperature dependence of CM phenolic extraction levels. The current study Syrah result is consistent with previous cold temperature Syrah results outlined here for CM.

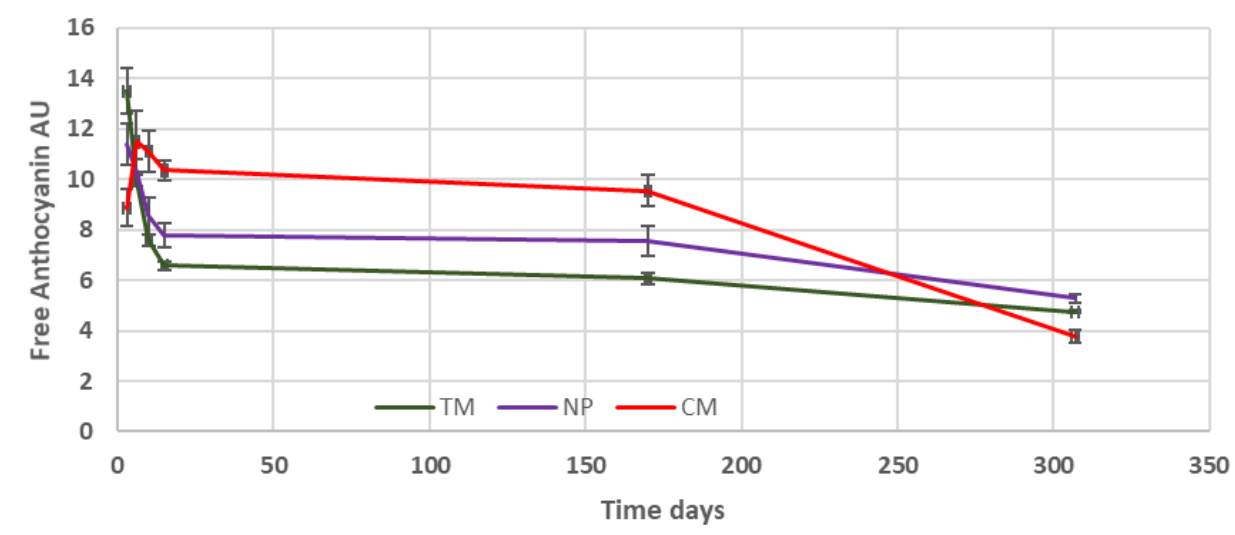

FIGURE 6

2016 Pinot Noir free anthocyanin content of the three winemaking procedures, beginning at day 1, expressed as Absorbance Units. TM. Traditional maceration. NP. Not plunged. CM Cold Maceration and not plunged. N=3 Error Bars \pm 1 Std Dev.

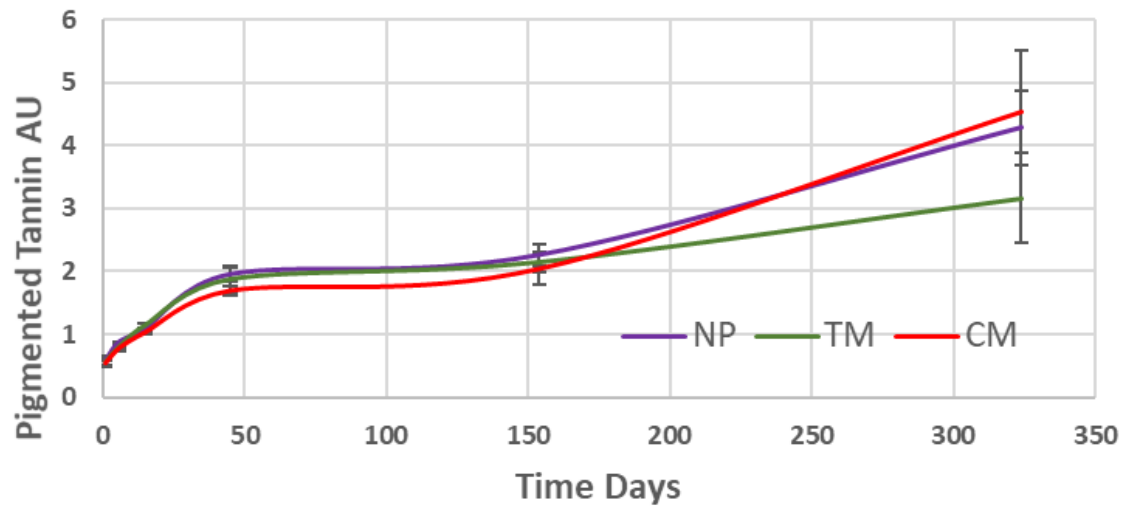

FIGURE 7

2015 Syrah pigmented tannin content of the three winemaking procedures, beginning at day 1, expressed as Absorbance Units. TM. Traditional maceration. NP. Not plunged. CM Cold Maceration and not plunged. N=3 Error Bars \pm 1 Std Dev. 


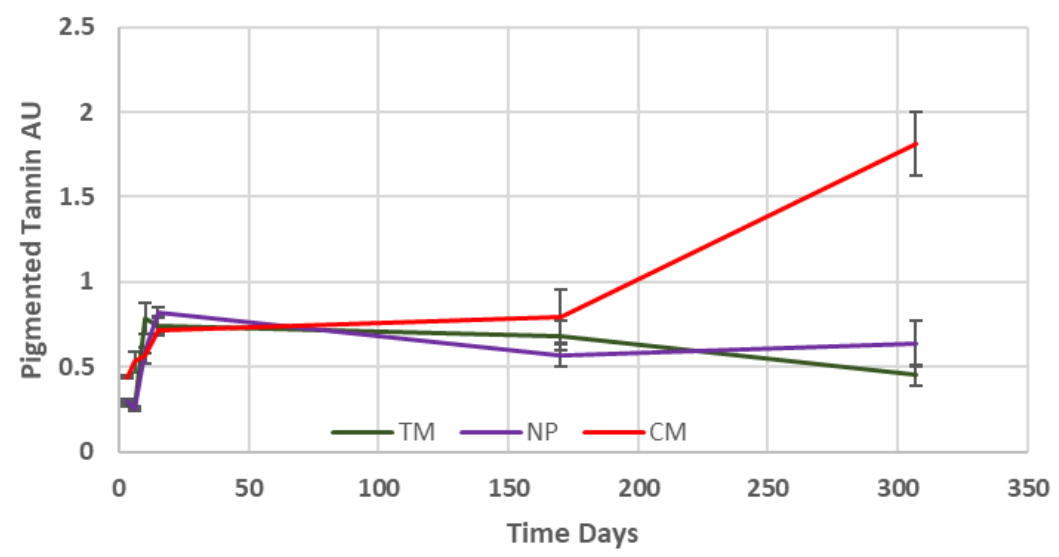

FIGURE 8

2016 Pinot Noir pigmented tannin content of the three winemaking procedures, beginning at day 1, expressed as Absorbance Units. TM. Traditional maceration. NP. Not plunged. CM Cold Maceration and not plunged. $\mathrm{N}=3$ Error Bars \pm 1 Std Dev.

CM has been found to have variable phenolic extraction results with Pinot noir. There is a low skin to seed tannin ratio with Pinot Noir compared with other red wine making varieties (Carew et al., 2013). These researchers also stated that seed tannin is more difficult to extract than skin tannin and that it is extracted later in the maceration. It is important to make sure that seed tannins are extracted during maceration in order to bring about colour stability. With a period of $\mathrm{CM}$ in the present study of 5 days it was possible to both extend the period of maceration and encourage increases in cell wall permeability through enzyme action, thus aiding the extraction of more easily extractable skin tannins. The extra time also aids the extraction of more seed tannins as the overall contact time of seeds and liquid is increased compared with the TM treatment. The effect of this with Pinot Noir is a higher skin (and pigment) to seed phenolic ratio leading to increased potential stabilised (pigmented tannin) colour. Syrah berries have higher amounts of skin phenolics (and pigment) available which is more easily and earlier extracted than seed phenolics, along with much higher seed phenolic availability compared with the Pinot Noir. This may mean that the Syrah CM is less likely to have any significant effect on total phenolic or colour extraction compared with NP only treatment.

Selective extraction and removal of tannin derived from grape skin and seed components may be dependent upon the point at which pulp cell wall binding sites become saturated with tannin (Sparrow et al., 2015). The differences between the Syrah CM/NP/TM treatments compared with the Pinot Noir extractions for the CM/NP/TM can be looked at in this light. It may be necessary to differentially extract and retain skin tannins early in winemaking process to give increases in colour stability in Pinot Noir wines, in other words to promote an increase in pigmented tannins.

Smith et al (2015) in a review of winemaking practices impacts on composition propose that $\mathrm{CM}$ facilitates the activity of endogenous grape enzymes in degrading cell wall structure, limits poly phenol oxidase activity or delays fermentation. Each of these might be expected to enhance either extraction or preservation of grape derived phenolic substances in wine. Or they suggest maybe $\mathrm{CM}$ simply extends maceration time to aid greater hydration of seeds leading to increased seed extraction. The suggestion from these studies is that the increased physical disruption of solid grape material by such actions as plunging and other cap management techniques causes increased selective adsorption of larger molecular weight phenolics earlier. This may bring about saturation of pulp cell wall sites and in the case of less mechanically disrupted grape solids there would be less of these sites and therefore less adsorption leading to higher apparent extraction in the NP/CM treatments compared with the TM.

\section{CONCLUSIONS}

Both varietal and winemaking differences have affected extraction levels and tannin evolution. The results show that with reduced disruption to the wine cap during maceration an increased level of extraction can result and that over the next year after pressing the wines will develop differently. Most markedly Pinot Noir wine produced using both a CM and an NP treatment developed significantly higher colour levels and pigmented tannin levels compared with TM and NP alone treatments. Whereas Syrah wines produced with NP and CM plus NP were similar in colour and overall phenolic extractions and had higher levels of both than the TM treatments. Reasons for this include varietal differences, maceration temperature, origin of phenolics extracted and subsequent adsorption or reactions of extracted tannins. The latter leading to their potential removal from the wine giving the appearance of lower extraction levels. Further research is needed to analyse phenolic binding, modifications and origins during CM and NP winemaking processes. Although microvinification methods can be shown to replicate commercial level winemaking processes in many aspects, it is important that further studies on commercial size fermentations using Pinot Noir with CM plus NP methods need to be carried out sowinemakers can be confident the results would translate to the commercial scale. 


\section{LITERATURE CITED}

Aleixandre-Tudo, J., L. \& Du Toit, W., J., 2018. Cold maceration applications in red wine production and its effect on phenolic compounds: A review. Food Sci. Technol. 95, 200-208.

AWRI, 2012. Sample Preparation Guide- analysing wine and ferment samples for tannin, colour and phenolics measures using the Wine Portal.

Bindon, K.A., Smith, P.A., Holt, H. \& Kennedy, J., 2010. Interactions between grape -derived proanthocyanidins and cell wall material. 2. Implications for vinification. J. Agric. Food Chem. 58(19), 10736- 10746.

Bosso, A., Guaita, M., Panero, L., Borsa, D. \& Follis, R., 2009. Influence of two winemaking techniques on polyphenolic composition and colour of wines. Am. J. Enol. Vitic. 60(3), 379-385.

Bosso, A., Panero, L., Petrozziello, M., Follis, R., Motta, S. \& Guaita, M., 2011. Influence of sumerged-cap vinification on polyphenolic composition and volatile compounds of Barbera wines. Am. J. Enol. Vitic. 62(4), 503511.

Busse-Valverde, N., Gomez-Plaza, E., Lopez-Roca, J., Gil-Munoz, R., Fernandez-Fernandez, J. \& Bautista- Ortin, A., 2010. Effect of different enological practices on skin and seed proanthocyanidins in three varietal wines. J. Agric. Food Chem. 58, 11333-11339.

Busse-Valverde, N., Gomez-Plaza, E., Lopez-Roca, J., Gil-Munoz, R., \& Bautista- Ortin, A., 2011. The extraction of anthocyanins and proanthocyanidins from grapes to wine during fermentative maceration is affected by the enological technique. J. Agric. Food Chem. 59, 5450-5455.

Carew, A., L., Smith, P., A., Close, D., C., Curtin, C. \& D., D.R., 2013. Yeast effects on Pinot Noir wine phenolics, color and tannin. J. Agric. Food Chem. 61, 9892-9898.

Casassa, L.F., Bolcato, E., A. \& Sari, S., E., 2015. Chemical, chromatic, an sensory attributes of 6 red wines produced with prefermentative cold soak. Food Chem. 174, 110-118.

Cerpa-Calderon, F.K. \& Kennedy, J.A., 2008. Berry integrity and extraction of skin and seed proanthocyanidins during red wine fermentation. J. Agric. Food Chem. 56(19), 9006-9014.

Chittenden, R., Annand, M., King, P. \& Russell, G., 2015. The effect of half plunging and no plunging as alternative winemaking techniques on phenolic extraction and pigment composition of wine. S. Afr. J. Enol. Vitic. 36(1), $134-145$

Dambergs, R., G., Mercurio, M., D., Kassara, S., Cozzolino, D. \& Smith, P.A., 2012. Rapid measure of precipitable tannins using ultraviolet spectroscopy and chemometrics- application to red wine and inter-laboratory calibration transfer. Applied Spectroscopy 66(6), 656-664.

de Beer, D., Joubert., E., Marais, J. \& Manley, M., 2006. Maceration before and during maceration: Effects on Pinotage wine phenolic composition, total antioxidant capacity and objective colour parameters. S. Afr. J. Enol Vitic. 27(2), 137-150.

Gao, L., Girard, B. \& Reynolds, A.G., 1997. Changes in anthocyanins and color characteristics of Pinot Noir wines during different vinification processes. J. Agric. Food Chem. 45, 2003-2008.

Gawel, R., 1998. Red wine astringency: a review. Aust. J. Grape Wine Res. 4, 74-95.

Gil-Munoz, R., Moreno-Perez, A., Vila-Lopez, R., Fernandez- Fernandez, J., I, Martinez-Cutillas, A. \& Gomez-Plaza, E., 2009. Influence of low temperature prefermentative techniques on chromatic and phenolic characteristics of Syrah and Cabernet sauvignon wines. Eur. Food Res. Technol. 228, 777-788.
Gil, M., Kontoudakis, N., Gonzalez, E., Esteruelas, M., Fort, F., Miguel Canals, J. \& Zamora, F., 2012. Influence of grape maturity and maceration length on color, polyphenolic composition, and polysaccharide content of Cabernet Sauvignon and Tempranillo wines. J. Agric. Food Chem. 60, 7988-8001

Gomez- Miguez, M., Gonzalez- Miret, M., L \& Heredia, F.J., 2007. Evolution of colour and anthocyanin composition of Syrah wines elaboratted with prefermenmtative cold maceration. J. Food Eng. 79, 271-278.

Gonzales- Neves, G., Gil, G., Barreiro, L. \& Favre, G., 2010. Pigment profile of red wines cv. Tannat made with alternative winemaking techniques. J. Food Comp. Anal. 23, 447-454.

Gonzales- Nevez, G., Gil, G., Favre, G., Hernandez, N., \& Traverso, S., 2013. Influence of winemaking procedure and grape variety on colour and composition of young red wines. S. Afr. J. Enol. Vitic. 34(1), 138-146.

Iland, P.G., Ewart, A. \& Sitters, J., 1993. Techniques for chemical analysis and stability tests of grape juice and wine. Patrick Iland Wine Promotions, Campbelltown, S Australia.

Kassara, S. \& Kennedy, J., A., 2011. Relationship between red wine grade and phenolics. 2. Tannin composition and size. J. Agric. Food Chem. 59, $8409-8412$

Kemp, B., S., Harrison, R. \& Creasy, G.L., 2011. Effect of mechanical leaf removal and its timing on flavan-3-ol composition and concentrations in Vitis vinifera L. cv. Pinot Noir wine. Aust. J. Grape. Wine. Res. 17, 270279 .

Kennedy, J., A. \& Jones, P., J., 2001. Analysis of proanthocyanidin cleavage products following acid-catalysis in the presence of excess phloroglucinol. J. Agric. Food Chem. 49(4), 1740-1746.

Kennedy, J.,A. \& Taylor, A., W., 2003. Analysis of PA's by high-performance gel permeation chromotography. J. Chromatogr., A(995), 99-107.

Kennedy, J.A. \& Hayasaka, Y., 2004. Compositional investigation of pigmented tannin. In: Waterhouse, A.L., \& Kennedy, J. A. (ed). Red wine color: Revealing the mysteries. American Chemical Society, Washington, DC. pp. 247-264

Kovac, V., Alonso, E., Bourzeix, M. \& Revilla, E., 1992. Effect of several enological practices on the content of catechins and proanthocyanidins of red wines. J. Agric. Food Chem. 40, 1953-1957.

Lattey, K.A., Bramley, B.R. \& Francis, I.L., 2010. Consumer acceptability, sensory properties and expert quality judgements of Australian Cabernet Sauvignon and Shiraz wines. Aust. J. Grape Wine Res. 16, 189-202.

Lee, J., 2010. Degradation kinetics of grape skin and seed proanthocyanidins in a model wine system. Food Chem 123, 51-56.

Lerno, L., Panprivech, S., Ponangi, R., Hearne, L., Blair, T., Oberholster, A. \& Block, D., E., 2018. Research note. Effect of pump-over conditions on extraction of phenolic compounds during Cabernet Sauvignon fermentation. Am. J. Enol. Vitic. Published on line March 132018.

Lerno, L., Reichenbacher, M., Ponangi, R., Hearne, L., Block, D., E. \& Oberholster, A., 2015. Effects of cap and overall fermentation temperature on phenolic extraction in Cabernet Sauvignon fermentations. Am. J. Enol. Vitic. 66(4), 444-453.

Marais, J., 2003. Effect of different winemaking techniques on the composition and quality of Pinotage wine. II. Juice/Skin mixing practices. S. Afr. J. Enol. Vitic. 24(2), 76-79.

Mercurio, M.D., ., D., D.R., Cozzolino, D., Herderich, M.J. \& Smith, P.A., 2010. Relationship between red wine grades and phenolics. 1. Tannin and total phenolics concentrations. J. Agric. Food Chem. 58, 12313-12319. 
Mercurio, M.D., D., D.R., Herderich, M.J. \& Smith, P.A., 2007. High throughput analysis of red wine and grape phenolics - adaptation and validation of methyl cellulose precipitable tannin assay and modified Somers color assay to a rapid 96 well plate formatt. J. Agric. Food Chem. $55,4651-4657$.

Panprivech, S., Lerno, L.A., Brenneman, C., A., Block, D., E. \& Oberholster, A., 2015. Investigating the effect of cold soak duration on phenolic extraction during Cabernet Sauvignon fermentations. Molecules 20, 7974-7989.

Parley, A., L., Vanhanen. \& Heatherbell, D., 2001. Effects of prefermentation enzyme maceration and extraction on colour stability in Pinot Noir wine. Aust. J. Grape Wine. Res. 7, 146-152.

Puertas , B., Guerrero, R., F., Jurado, M., S., Jimenez, M., J. \& CantosVillar, E., 2008. Evaluation of alternative winemaking processes for red wine colour enhancement. Food Sci. Technol. Int. 14, 21-27.
Ribereau-Gayon, P., Glories, Y., Maujean, A. \& Dubourdieu, D., 2006. Hand book of Enology. The Chemistry of Wine Stabilization and Treatments. John Wiley \& Sons Ltd, Chichester.

Sacchi, K., L., Bisson, L., F. \& Adams, D., O., 2005. A review of the effect of winemaking techniques on phenolic extraction in red wines. Am. J. Enol. Vitic. 56(3), 197-206.

Smith, P., A., McRae, J.M. \& Bindon, K.A., 2015. Impact of winemaking practices on the concentration and composition of tannins in red wine. Aust. J. Grape. Wine. Res. 21(S1), 601-614.

Somers, T.C. \& Evans, M.E., 1977. Spectral evaluation of young red wines Anthocyanin equilibria, total phenolics, free and molecular SO2, "chemical age.". J. Agric. Food Chem. 28, 279-287.

Sparrow, A., M., D., D.R., Bindon, K.A., Smith, P., A. \& Close, D., C., 2015. Interactions of grape skin, seed, and pulp on tannin and anthocyanin extraction in Pinot Noir wines. Am. J. Enol. Vitic. 66(4), 472-481. 